development, rather than merely judging them against a list of criteria set by the Royal College of Psychiatrists.

The current drive towards evidence-based practice

original papers

also has a bearing on these findings. The technique of setting well-defined clinical questions based on cases seen in practice may be the ideal model for trainees to develop both clinical skills and knowledge. Detailed familiarity with the training syllabus would not be essential for such a task, and the exercise would almost certainly benefit trainee, supervisor and patient alike. Once under way, a rolling programme of setting a question, searching for evidence, appraising the evidence and applying the findings should be relatively easy to maintain, and could give structure to a supervision programme (Sackett et al, 1997).

Encouragement to attend local teaching programmes and cover for supervisor's absence were not considered a high priority by respondents, possibly because they seemed to be happening regularly. It is also not surprising that trainees did not appear to receive or seek career counselling from their educational supervisors. It may be that a trainee would seek out other sources of advice, possibly from the local tutor, a 'mentor' figure or a doctor already practising the trainee's speciality of interest. We suspect that educational supervisors offer advice where they feel it is appropriate, but are prepared to refer their trainee on to others to supplement this.

In conclusion, the results of this survey clearly inform the training agenda for trainers. Herriot et al (1994) concluded that supervision needed to be:

"timetabled and planned at the beginning of the post, with an agenda being set reflecting the individual trainee's previous experience, strengths, weaknesses and interests".

Our results suggest that this may not be enough. Similar research with higher specialist trainees in the North Thames Region has also emphasised the trainees' desire for their educational supervisors to focus on individual goals and professional development, while acknowledging the need for improved training (Riley, 1998). They have identified the key features that a training programme for educational supervisors should have, emphasising the need to work within time and funding constraints. It would seem important that such a programme is delivered in our region and across the country, particularly if a good experience of appraisal as a junior trainee leads to the development of a clear plan for continuing professional development and to even better educational supervision in the future. In the meantime, educational supervisors must be reminded of the need to offer a weekly hour-long session with their trainees as a minimum for delivering good quality support and guidance.

\section{Acknowledgement}

We would like to thank Mrs M. Calcutt for her assistance with the production of the questionnaire.

\section{References}

COTTRELL, D. (1999) Supervision. Advances in Psychiatric Treatment, $\mathbf{5}$, 83-88

DEPARTMENT OF HEALTH (1996) A Guide to Specialist RegistrarTraining. London: Department of Health

HERRIOT, P., BHUI, K. \& LELLIOTT, P. (1994) Supervision of trainees. Psychiatric Bulletin, 18, 474-476.

KATONA, C. (1998) Ensuring the skills of tomorrow's psychiatrists. Psychiatric Bulletin, 22, 659-661.

KING, J. (1999) Giving feedback. British Medical Journal, 318, 2-3.

KINGSBURY, S. \& ALLSOPP, M. (1994) Direct consultant supervision of higher trainees in child and adolescent psychiatry. A survey of expectations and practice. Psychiatric Bulletin, 18, $225-229$

ROYAL COLLEGE OF PSYCHIATRISTS (1995) Handbook for Inceptors and Trainees in Psychiatry. London: Royal College of Psychiatrists.

RILEY,W. (1998) Appraising appraisal. British Medical Journal, 316, 2-3.

SACKETT, D., RICHARDSON,W., ROSENBERG,W., et al (1997) EvidenceBased Medicine. How to Practice and

*Edward Day Senior House Officer in General Adult Psychiatry, Nick Brown Organising Tutor, All Birmingham Rotational Training Scheme in Psychiatry and Consultant Psychiatrist, Lyndon Clinic, Hobs Meadow, Solihull, B92 8PW

\title{
DAVID VEALE
}

\section{Outcome of cosmetic surgery and 'DIY' surgery in patients with body dysmorphic disorder}

\section{AIMS AND METHOD}

Little is known about the outcome of cosmetic surgery in patients with body dysmorphic disorder (BDD). Self-reported outcome was collected on 25 patients with BDD who at the time of psychiatric assessment had reported that they had had cosmetic surgery in the past.

RESULTS

Twenty-five patients with BDD had a total of 46 procedures. The worst outcome was found in those who had had rhinoplasty and those with repeated operations. Mammoplasty and pinnaplasty was associated with higher degrees of satisfaction. Nine patients with $\mathrm{BDD}$, either in desperation at being turned down for cosmetic surgery or because they could not afford it, had performed their own 'DIY' surgery in which they attempted by their own hand to alter their appearance dramatically.

\section{CLINICAL IMPLICATIONS}

Cosmetic surgery cannot at present be recommended for patients with BDD. However, patients turned down for surgery or who cannot afford it, may try to alter their appearance by themselves. The study contains a selection bias of patients in favour of treatment failures in cosmetic surgery and prospective studies are required on BDD patients who obtain cosmetic surgery or dermatological treatment. 
Body dysmorphic disorder (BDD) is characterised by a preoccupation with an imagined defect or a markedly excessive concern, where there is a slight physical anomaly (DSM-IV; American Psychiatric Association, 1994). Many patients with BDD crave to change their appearance by cosmetic surgery or by dermatological treatments. I have previously reported that in 50 patients with BDD in the UK, $26 \%$ had managed to obtain one or more cosmetic operations (Veale et al, 1996a). There are no outcome studies of cosmetic surgery in BDD apart from Phillips et al (1993) who reported on eight patients who had between them undergone 25 plastic or dental surgery procedures. Only two procedures led to an improvement of remission of symptoms while 20 procedures resulted in an exacerbation of symptoms. BDD is not uncommon in cosmetic surgery clinics. In a recent survey of 100 women seeking cosmetic surgery in the USA, 5\% met the diagnostic criteria for BDD (Sarwer et al, 1998). This paper reports both on BDD patients seen in the UK about their experience of cosmetic surgery and on the occurrence of DIY cosmetic surgery in patients unable to obtain the surgery they crave.

\section{The study}

Data were collected on 25 patients with BDD who reported at the time of psychiatric assessment that they had had cosmetic surgery in the past. Referrals were from their general practitioner $(n=8)$, a consultant psychiatrist $(n=7)$, or self-referral or via a patient support group $(n=10)$. Patients were asked to rate:

(a) the degree of satisfaction with the outcome of each operation they had had on a scale between zero and 10 , where zero represented extreme dissatisfaction and 10 extreme satisfaction;

(b) any change in the overall amount of time they took and distress they experienced thinking about their appearance after the operation on a scale between one and seven where one represented 'very much less' and seven was 'very much more' (Guy, 1976);

(c) any change in the overall degree of handicap in relation to their occupational and social life after the operation on the same scale as above.

Patients were also asked if after an operation the preoccupation transferred to another area of the body.

\section{Findings}

The sample consisted of 25 patients with BDD who had had a total of 46 procedures. Ten patients had undergone one procedure, 10 patients had undergone two procedures, four patients had undergone three procedures, and one patient had undergone four procedures. They had a mean age of 36.0 years (range $22-63$ ) and $12 \%$ of the sample was male. The operations had occurred a mean of 5.6 years ago. Twenty-six per cent of the operations were performed on the NHS. Many of those who had had private cosmetic surgery had taken out loans or borrowed from relatives.

Three patients claimed that they were not preoccupied by their appearance prior to the surgery and that their symptoms of BDD developed only after surgery, which they believed had been done badly. The satisfaction ratings and any change in preoccupation and overall handicap are listed in Table 1. The numbers of several procedures are small but the satisfaction ratings tended to be higher for mammoplasty, rhytidectomy (face-lift) and pinnaplasty. Mammoplasty and pinnaplasty (but not rhytidectomy) tended to lead to an overall decrease in preoccupation and handicap.

The satisfaction rating was relatively low for rhinoplasty, which was the most common procedure. The nose is also the most usual location for complaint by patients with BDD (Veale et al, 1996a). Rhinoplasty tended to be associated with an increase in preoccupation and handicap. Most of the patients in the study had multiple

Table 1. Ratings of satisfaction, preoccupation and handicap for each type of operation

\begin{tabular}{|c|c|c|c|c|}
\hline Operation & $n$ & $\begin{array}{l}\text { Satisfaction, } \\
\text { range } 0-10, \text { mean (s.d.) }\end{array}$ & $\begin{array}{l}\text { Preoccupation, } \\
\text { range } 1-7, \text { mean (s.d.) }\end{array}$ & $\begin{array}{l}\text { Handicap, } \\
\text { range } 1-7 \text {, mean (s.d.) }\end{array}$ \\
\hline Rhinoplasty & 22 & $2.9(2.7)$ & $4.4(1.4)$ & $4.5(1.5)$ \\
\hline Rhytidectomy (face-lift) & 4 & $6.0(3.6)$ & $3.7(2.5)$ & $4.0(2.0)$ \\
\hline Mammoplasty augmentation & 3 & $6.3(3.5)$ & $3.7(2.3)$ & $2.0(1.0)$ \\
\hline Blepharoplasty (eye-lid) & 2 & $3.7(1.2)$ & $5.5(0.7)$ & $5.0(1.4)$ \\
\hline Pinnaplasty (pinning of ears) & 4 & $5.3(3.8)$ & $2.0(1.4)$ & $2.0(1.4)$ \\
\hline Abdominoplasty (tummy-tuck) & 1 & 2.0 & 3.0 & 4.0 \\
\hline Chemical peel (to face) & 1 & 2.0 & 3.0 & 3.0 \\
\hline Laser resurfacing (to face) & 1 & 2.0 & 3.0 & 4.0 \\
\hline Hair transplant & 1 & 0.0 & 7.0 & 6.0 \\
\hline Removal of mole on face & 1 & 2.0 & N/A & N/A \\
\hline Removal of thread veins by sclerotherapy & 1 & 2.0 & 3.0 & 4.0 \\
\hline
\end{tabular}


Table 2. Satisfaction with repeated operation

original papers

\begin{tabular}{|lrlll}
\hline Operation & $n$ & $\begin{array}{l}\text { Satisfaction, } \\
\text { range 0-10, } \\
\text { mean (s.d.) }\end{array}$ & $\begin{array}{l}\text { Preoccupation, } \\
\text { range 1-7, } \\
\text { mean (s.d.) }\end{array}$ & $\begin{array}{l}\text { Handicap, } \\
\text { range 1-7, } \\
\text { mean (s.d.) }\end{array}$ \\
\hline First & 25 & $3.9(3.3)$ & $4.4(1.5)$ & $4.1(1.5)$ \\
Second & 15 & $2.8(2.5)$ & $4.5(2.0)$ & $4.2(1.9)$ \\
Third & 5 & $2.8(1.9)$ & $4.7(1.3)$ & $4.5(1.7)$ \\
\hline
\end{tabular}

concerns about their appearance and reported that after $50 \%$ of the procedures the preoccupation transferred to another area of their body. After one procedure, the mean satisfaction rating was 3.9 (see Table 2). By the second or third procedure, this had dropped to 2.8. The second or third procedure was not always a revision of the first procedure. For example, of the 17 patients who had rhinoplasty, only three underwent one or more revisions and 14 had a different procedure when their preoccupation moved to a different area of the body. When patients were dissatisfied with their operation, they often felt guilty or angry with themselves or the surgeon for having made their appearance worse, thus further fuelling their depression and a failure to achieve their ideal. This in turn tended to increase mirror gazing and craving for more surgery. Six patients rated themselves as satisfied with their procedure (defined as a rating of 7-10). Four of these patients went on to have one or more further procedures or were dissatisfied with another area of their body but did not have further surgery.

\section{'DIY' cosmetic surgery}

Nine patients with BDD (of whom two were included in the sample above) reported performing their own cosmetic surgery in which they attempted to alter their appearance dramatically. This was either in desperation at being turned down for cosmetic surgery or because they could not afford it. The procedures were often associated with many hours of mirror gazing and intense disgust at their perceived defect. Examples of the procedures that were undertaken are shown in the Appendix. All cases were dissatisfied with the results of their own attempts at surgery.

\section{Comment}

Most patients with BDD reported a high degree of dissatisfaction with cosmetic surgery and an increase in their symptoms of BDD or overall handicap. Repeated surgery tended to lead to increasing dissatisfaction. Some operations, such as rhinoplasty appear to be associated with higher degrees of dissatisfaction. Mammoplasty and pinnaplasty tended to have relatively higher satisfaction ratings. These operations tend to be unambiguous in that the patient can usually describe the problem that concerns them and their desired outcome and the cosmetic surgeon can understand their expectations.

Even when patients were partially or wholly satisfied with the results then the preoccupation transferred to a different area of the body and they remained significantly handicapped in their symptoms of BDD. There is a suggestion that the onset of BDD for some patients occurred after cosmetic surgery although this needs confirmation in a larger prospective study of patients before cosmetic surgery.

The main weaknesses of this study and that of Phillips et al (1993) are:

(a) The data are retrospective and there is a selection bias of patients in favour of treatment failures. Mental health practitioners are unlikely to see patients with BDD who might be satisfied with their cosmetic surgery and have overcome their symptoms of BDD. However, at this stage, it is not known what factors might predict satisfaction in patients with BDD who undergo surgery and in whom the preoccupation does not transfer repeatedly to another area of the body.

(b) A variety of different cosmetic operations were under scrutiny and it is difficult to interpret the success of some operations which have only one or two procedures in this sample.

(c) There is no control group of psychiatric patients who have undergone cosmetic surgery but do not have BDD. However, the majority of individuals (who do not have BDD) are very satisfied with cosmetic surgery and their self-esteem and other psychological measures improve (Klassen et al, 1996; Carr et al, 2000).

There is, however, never likely to be a randomisedcontrolled trial of cosmetic surgery in patients with BDD comparing, for example, cognitive-behavioural therapy (Veale et al, 1996b) or a serotonin reuptake inhibitor (Hollander et al, 1999). At best, a prospective study of patients with BDD undergoing specific cosmetic surgery operations with a long-term follow-up is required to determine efficacy in the long term and whether patients eventually become satisfied after several operations.

The motivation for DIY surgery is complex, but it appears primarily either to camouflage a perceived defect or to try to achieve an unrealistic ideal. It does not fit the existing classification of self-harm by Favazza \& Rosenthal (1993). It has a similar poor psychological outcome in so far as nearly all the patients were dissatisfied with their handiwork and found their symptoms of BDD were exacerbated. It reflects the extreme measures that some patients take and is mirrored in the high rate of attempted suicide in this population (Veale et al, 1996a).

\section{Acknowledgement}

I would like to thank Susan Riley, Assistant Psychologist, for help in collection of the data and Dr Marc Serfaty for his comments.

\section{References}

AMERICAN PSYCHIATRIC ASSOCIATION (1994) Diagnostic and Statistical Manual of Mental Disorders (DSM-IV) (4th edn). Washington, DC: American Psychiatric Press.
CARR, A. T., HARRIS, D. L. \& JAMES, C. (2000) The Derriford Appearance Scale (DAS59): a new rated self-report questionnaire. British Journal of Health Psychology, in press. 
FAVAZZA, A. R. \& ROSENTHAL, R. J. (1993) Diagnostic issues in selfmutilation. Hospital and Community Psychiatry, 44, 134-140

GUY,W. (1976) Assessment Manual for Psychopharmacology. Washington, DC National Institute of Mental Health, US Department of Health, Education and Welfare.

HOLLANDER, E., ALLEN, A., KWON, J., et al (1999) Clomipramine vs desipramine crossover trial in body dismorphic disorder. American Journal of Psychiatry, 56, 1033-1042.

KLASSEN, A., FITZPATRICK, R., JENKINSON, C., et al (1996)

Should breast surgery be rationed?

A comparison of the health status of patients before and after treatment: postal questionnaire survey. British Medical Journal, 313, 454-457.

\section{Appendix}

\section{Examples of DIY cosmetic surgery}

A man preoccupied by his skin who believed that it was too 'loose'. He used a staple gun on both sides of his face to try to keep his skin taut. The staples fell out after 10 minutes and he narrowly missed damaging his facial nerve.

A woman preoccupied by her skin and the shape of her face. She filed down her teeth in order to alter the appearance of her jaw-line.

A man who was preoccupied with the appearance of his chin deliberately cycled into the back of a lorry in an attempt to fracture his jaw so that it could be reset in a way that he wanted. At the last moment, he decided against the plan, dropped his head, cut his forehead and fractured his skull.

A man preoccupied by his facial skin said he had used sandpaper as a form of dermabrasion to remove scars and to lighten his skin.

A man who was preoccupied by redness on his skin repeatedly exsanguinated himself by a syringe and needle or when he was accepted, by going to blood transfusion clinics to 'make himself look paler'.

A woman who was preoccupied by the ugliness of multiple areas of her body who desired liposuction but could not afford it, used a knife to cut her thighs and attempted to squeeze out the fat.

David Veale Consultant Psychiatrist, Department of Psychiatry and Behavioural Sciences, Royal Free and University College Medical School, University College, c/o Grovelands Priory Hospital, The Bourne, Southgate, London N14 6RA 